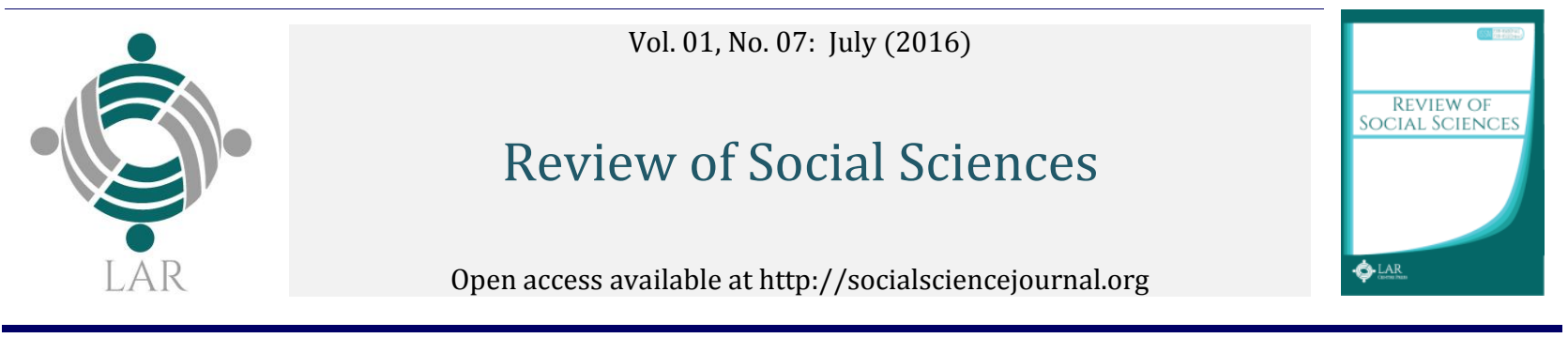

\title{
Sustaining a Regime of Low Fertility
}

\author{
Kaberi Gayen, $\mathrm{a}^{*}$, Robert Raeside ${ }^{\mathrm{b}}$ \\ a Professor, Department of Mass Communication and Journalism, University of Dhaka, Dhaka, Bangladesh \\ Email: gayenkaberi@gmail.com \\ b Professor, Employment Research Institute, Edinburgh Napier University, Edinburgh, Scotland. \\ ${ }^{*}$ Corresponding author's email address: r.raeside@napier.ac.uk
}

\section{Keywords: \\ Communication; \\ Low fertility; \\ Reciprocal ties; \\ Social networks; \\ Bangladesh.}

A R T I C L E I N F O

Received: 04-07-2016

Accepted: 27-07-2016

Available online: 31-07-2016

JEL Classification: C21, I12, J10, J13.

\section{A B S T R A C T}

In several developing countries, notably Bangladesh, fertility rates fell dramatically in the later part of the twentieth century and have sustained at low levels. Traditional socioeconomic models do not fully explain the profile of fertility fall especially for rural areas where well-being has not sufficiently improved. This paper offers a supplementary explanation that mass media facilitated the diffusion of contraceptive knowledge, leading to an ideological shift to value small families, and social networks especially reciprocal encouragement about contraception practice among network members has helped to sustain this shift. To investigate the role of encouragement of immediate network members in their family planning behavior, data was gathered using an interview-based survey of 694 women of fertile ages in seven rural Bangladeshi villages. Findings give support to the importance of social networks in maintaining achieved low fertility levels. When there is strong reciprocal encouragement of network members about practicing contraception then using contraception is more likely. This we propose may offer an explanation to why a low fertility regime has endured in Bangladesh. From this study policy recommendations are made to sustain low fertility.

This is an open access article under the terms of the Creative Commons Attribution License 4.0, which allows use, distribution and reproduction in any medium, provided the original work is properly cited.

\section{Introduction}

Towards the end of the twentieth century, many developing countries exhibited steady falls in fertility as measured by the total fertility rate. In most of these countries, economic growth was slight or even negative. Thus, questions were asked about the traditional association of economic growth and demographic transitions that economic growth resulted in fertility falls, (Davis, 1945; Cleland and Wilson, 1987; Caldwell and Caldwell, 2006). In Bangladesh in 1970 the total fertility rate (TFR) was 7.5 children per woman and by 2001 fertility had fallen to 2.78 and in 2015 the TFR was 2.23, (UN 2016). Over this period the Bangladesh economy remained weak and it is estimated by the International Fund for Agriculture Development, (IFAD, 2014) that 43.8\% of the rural populous live in poverty. Explanations for the fertility fall are credited to the success of an all-out communications campaign by the Government of Bangladesh supported by non-governmental organisations, (Bangladesh Centre for Communication Programs, 2003; Gayen and Raeside, 2010) and to falls in infant mortality. According to the World Bank, (2014) infant mortality has fallen from 103.5 per 1,000 in 1990 to 38.0 per 1000 in 2010. This campaign emphasised the benefits of low fertility to improving the well-being of the family and contributed to achieving an ideational change from the belief that many children are needed to support the family to one where a more rational choice occurs (Kincaid, 2000). Gayen and Raeside, (2010) have 
shown that interpersonal contacts within social networks are important to facilitate this change and being socially connected to people who are open to change and give endorsement is necessary whereas being connected to those who are resistant to change and promote traditional ways are important constraints. However, since the beginning of the twenty first century especially amongst rural women there is little improvement to the quality of life yet the regime of low fertility continues. We suggest that this may be an expression of the enduring power of social networks and in particular the importance of reciprocal ties between actors who support the small family norm.

Our aim in this paper is to revisit data collected for investigating the association between social networks and fertility that was collected in 2004 and in particular the extent of reciprocal endorsements of behaviour a feature that has not previously been analysed in this data. We will use this data in an attempt to demonstrate the importance of mutual encouragement (a reciprocal link) to the sustaining of a regime of low fertility. First a short literature review is given, followed by an outline of methods used to collect data and undertake the analysis. Results are then presented and the paper concludes with a discussion.

Reciprocal ties describes a relationship in which two people feel the same way about each other, or perceive about a thing or idea in a similar way, or exchange similar ideas or things within themselves. Reciprocity is an important social network property. According to Hanneman and Riddle (2005), "A common interest in looking at directed dyadic relationships is the extent to which ties are reciprocated. A network that has a predominance of null or reciprocated ties over asymmetric connections may be a more "equal" or "stable" network than one with a predominance of asymmetric connections (which might be more of a hierarchy)." The power of reciprocity is not evident only in socio-economic system and human social organisations, but also in uncovering the essential function of directed social networks.

Theoretically reciprocal data is used in many situations however in health and family planning research there is rarely any research which collected data using a full network approach. Mainly data is collected using an ego centric approach which precludes identification of reciprocity. In the more frequently conducted ego centric network approach only the ego's opinion can be collected and the perceived behaviour about the alter can be recorded at the best. However, in the full network approach it is possible to check both egos and alters behaviour and opinions. This allows our research to offers a novel opportunity to identify reciprocity in the network. Our paper bridges the gap in the literature relating to empirical studies of the relationship of reciprocal encouragement to fertility. The approach also allows a wider range of social network properties to be used rather than just size and density.

\subsection{Literature Review}

To provide insight into the effect of social relations on decision making of individuals the use of the methodology of Social Network Analysis (SNA) is appropriate. Wasserman and Faust in 1998 described SNA as a means of identifying and understanding patterns of interactions amongst actors whether these actors are people, animals or organisations. The focus of attention is on the link or tie between actors and it is the flow of information or ideas or influence across these ties that is analysed. Particular interest is in the degree of connectedness to other actors and the position of actors in a network. If an actor has many ties going to them or emanating from them then they are said to be central in the network. Other important concepts are actors who are bridges between two or more groups and so have important moderating effects on flows across the ties between groups and structural holes in the network where there is a lack of connecting ties. A powerful way of visualising a social network is the sociogram, which provides a map of how actors are connected to one another, (Hogan, Carrasco and Wellman, 2007). A contemporary treatment of SNA is provided by Borgatti, Everett and Johnson (2013).

The methodology does however, have some practical problems notably identifying the full network, it is very difficult to identify and include all actors who may have influence in the network and identifying causal effects is almost impossible. For example, if in a study of whether or not girls smoke cigarettes one finds that girls who smoke have a network of other smokers. It is dangerous to conclude that the girl has fallen in to bad company and the group influences her to take up smoking. It might be simply that like-minded individuals are attracted to one another - a principle referred to as homophile. Nevertheless SNA has given powerful insights into human behaviour, (Ryan, 2011; Van der Hulst, 2009) and has been applied to understand health related behaviours (see for example Gayen and Raeside. 2010, Valente, 2010, Latkin et al. 2003 and Luke and Harris, 2007).

One of the seminal studies showing the value of social networks to explain contraceptive behaviour was that by Kincaid, (2000) who demonstrated that social connectedness was an important explanatory variable to women in rural Bangladeshi villages accepting family planning and using modern contraceptive methods. The importance of social connections to reproductive behaviour is reported by Montgomery and Casterline, (1996) 
and Valente, Watkins and Jato (1997) and several other studies (see for example Boulay and Valente, 1999; Godley 2001; Stoebenau and Valente, 2003; Madhavan, Adams and Simon, 2003; Babola and Vonrasek, 2005). Gayen and Raeside, (2007 and 2010) showed that links between women, which contained women who advocated traditional practices inhibited uptake of contraception, modern medical ideas and made the use of medical centres and professionals less likely. On the other hand if women in their networks approved of modern contraceptive methods this made the uptake of modern contraception significantly more likely.

The impact of social networks is thought to be stronger if ties between actors are reciprocal, that is there is mutual endorsement between actors, (Curry, Roberts and Dunbar, 2001; Xue, 2013). From a study of UK civil servants, Chandola, Marmot and Siegrist (2007) showed that if ties are not reciprocal then arising from the imbalance between effort and reward poor health could result. When studying the health of older people Li and Zhang (2015) found that reciprocal ties were especially good for enhancing health outcomes. They also found that friend based networks were better than family based networks for securing physical health outcomes but not for psychological outcomes. Stewart-Williams, (2007) suggested that these reciprocal relationships are likely to be less important for kin than for friends, an important observation for rural Bangladesh where kinship ties are strong. There have been few reported studies in this area and the authors are unaware of any in reproductive health and it is in this area that this paper contributes.

\subsection{Methods}

In 2004 a survey was undertaken, by the authors, of women of childbearing age, (taken for the purposes of this study to be 15 to 45 years) in seven rural villages in Bangladesh. The villages were chosen such that they had non-contiguous boundaries and because of the difficulties of women travelling in rural Bangladesh, this meant that networks tended to be confined to the village. This helped to mitigate against one of the major difficulties of SNA - that of identifying the full network, of course there are still influences from those external to the village such as siblings who migrated to cities or are working overseas. Women of reproductive age, who was married and had at least one child, were interviewed and the interviewer completed a questionnaire. The women interviewed reported on their social and demographic background, including; their age, number of children, experience of child death, years of education (coded 0 for no schooling, 1 for primary and 2 for secondary or above), permission to travel unaccompanied, female participation in decision making and number of possessions. From combining questions of permission to travel unaccompanied outside their home measured on a scale from never to always, hours worked outside the home and decision-making power in household matters measured on a five-point scale from none through equally with husband to normally the sole decision maker, an indicator of female autonomy status was formed. Principal component analysis was used to create the indicator by taking the first principal component, which accounted for $79.6 \%$ of the original variation. For further particulars of the data collection and variables used, see Gayen, (2009). The respondents were also asked what religion they adhered to ( $1=$ Muslim, $0=$ other) and if they were in a micro credit organisation as being so is associated with contraception use, (see Amin, Li and Ahmed, 1996). The women were then asked to report on their fertility behaviour; whether or not they use contraception (which will be used as an outcome variable) currently, contraceptive method used, use of modern medical services and how they received information relating to family planning. The respondents were then asked to rate on an eleven-point scale the degree of influence they perceived to practice contraception were given by husbands, mass media, (mainly radio and TV) and female welfare assistants. ( 0 was no influence and 10 was a high degree of influence). The last part of the interview involved obtaining socio-metric data. Here women reported on the nature of their contacts with up to five friends who reside outside the respondents' household. Questions asked were frequency of meeting and importance of contacts, if discussed family planning, if the contact practiced family planning and two questions important to this study, aimed to enquire into reciprocity:

1. Does your contact encourage you to use contraception?

2. Do you encourage your contact to use contraception?

Respondents reported on these questions on a scale never encouraged $=0$, a little encouragement $=1$, moderate encouragement $=2$, strong encouragement $=3$. Two "strength of encouragement" scores (encouragement from others and encouragement to others) were created by multiplying these variables by the frequency they discussed family planning. Frequency of meeting and discussing family planning were recorded on a scale $0=$ never, $1=$ occasionally, $2=$ often and $3=$ frequently.

The survey was given ethical approval by the Research Degrees committee at Edinburgh Napier University and after piloting, some 694 women responded to the survey. The demographic and socio-economic summary of the sample is reported in Table 1. The proportion of those stating they were of the Hindu faith is much higher than given in national surveys, this was due to the deliberate inclusion of village 7 known to be predominantly Hindu, 
this was done to allow comparison of contraception rates between those adhering to Islam with those adhering to Hinduism.

Table 1: Summary of the respondents' demographic and socio-economic circumstances

\begin{tabular}{|c|c|c|c|c|c|c|c|c|}
\hline Variable & V1 & $\mathrm{V} 2$ & V3 & V4 & V5 & V6 & V7 & All \\
\hline Sample size & 63 & 74 & 97 & 84 & 196 & 97 & 81 & 694 \\
\hline Percentage practicing contraception & $67.0 \%$ & $66.0 \%$ & $36.0 \%$ & $62.0 \%$ & $85.0 \%$ & $68.0 \%$ & $73.0 \%$ & 68.0 \\
\hline Percentage who were Hindu & $36.5 \%$ & $33.8 \%$ & $0.0 \%$ & $4.8 \%$ & $14.2 \%$ & $46.5 \%$ & $95.1 \%$ & $\begin{array}{r}29.1 \\
\%\end{array}$ \\
\hline Percentage in a micro credit organisation & $61.9 \%$ & $23.0 \%$ & $13.4 \%$ & $2.2 \%$ & $60.4 \%$ & $41.8 \%$ & $34.6 \%$ & $\begin{array}{r}39.5 \\
0 \%\end{array}$ \\
\hline Mean women's age & 25.94 & 25.83 & 28.63 & 28.86 & 28.9 & 28.66 & 28.06 & 28.09 \\
\hline Mean number of children & 2.22 & 2.53 & 3.65 & 2.7 & 2.59 & 2.53 & 2.2 & 2.66 \\
\hline Mean number of dead children & 0.13 & 0.49 & 0.46 & 0.51 & 0.18 & 0.28 & 0.05 & 0.29 \\
\hline $\begin{array}{l}\text { Percentage of women with secondary } \\
\text { school education }\end{array}$ & $27.0 \%$ & $24.4 \%$ & $18.5 \%$ & $6.0 \%$ & $12.3 \%$ & $33.7 \%$ & $18.5 \%$ & $\begin{array}{r}18.8 \\
\%\end{array}$ \\
\hline $\begin{array}{l}\text { Percentage of husbands with secondary } \\
\text { school education }\end{array}$ & $33.4 \%$ & $33.8 \%$ & $20.6 \%$ & $9.6 \%$ & $26.0 \%$ & $49.0 \%$ & $32.1 \%$ & $\begin{array}{r}29.0 \\
\%\end{array}$ \\
\hline Mean possession score & 2.60 & 3.19 & 1.73 & 1.27 & 1.66 & 2.61 & 3.42 & 2.62 \\
\hline Mean female autonomy score & 0.49 & -0.75 & -0.43 & -0.54 & 0.35 & -0.25 & 0.79 & -0.01 \\
\hline Mean husband influence & 2.11 & 4.92 & 2.65 & 4.55 & 2.76 & 6.78 & 4.75 & 3.93 \\
\hline Mean Family welfare assistant influence & 2.00 & 1.64 & 1.03 & 4.39 & 7.41 & 2.88 & 5.95 & 4.23 \\
\hline Mean Mass Media Influence & 0.25 & 1.10 & 1.10 & 0.48 & 2.89 & 1.12 & 1.41 & 1.5 \\
\hline Encouragement by opinion leaders & 0.00 & 0.08 & 0 & 0.00 & 0.02 & 0.11 & 0.00 & 0.03 \\
\hline t by friends & 3.07 & 2.65 & 1.77 & 2.65 & 0.47 & 1.48 & 0.12 & 1.49 \\
\hline Encouragement by relatives & 3.06 & 2.91 & 1.53 & 3.45 & 3.27 & 1.39 & 1.69 & 2.54 \\
\hline Encouragement to others & 5.70 & 4.82 & 2.53 & 4.73 & 3.76 & 2.21 & 1.53 & 3.52 \\
\hline
\end{tabular}

From Table 1 it is apparent that there is a considerable variation in the practice of contraception. Contraception rates are lowest when the village is more Islamic, has lower representation of women in micro credit organisations, low possession scores, low scores on the female autonomy index and low levels of encouragement (which are on average very low as many receive no encouragement).

The social network data were used to test the association of encouragement to use contraception and actual use of contraception while controlling for the demographic and socio-economic factors. To do this a binary logistic model was constructed to ascertain the likelihood of using contraception. Finally the importance of reciprocal links' was explored by importing the data relating to 'if the ego encourages their alter to use contraception' and vice versa into the SNA package UCINET, (Borgatti, Everett and Freeman, 2002) and important actors are identified. Variables derived from this analysis were used to add insight. Important actors in this case were identified as having high out-degree centrality that is a measure formed from the sum of the encouragement scores they give to others. In-degree centrality will also be computed which is the sum of the encouragement scores a respondent receives from others. It was hypothesised that in and out degree centrality was closely correlated and that these in turn would correlate positively to the likelihood of using contraception. To illustrate the pattern of relations amongst respondents and if this is associated with contraception practised, sociograms were constructed. In this paper, for brevity, these are presented for the villages with highest and lowest levels of contraceptive practice, villages 3 and 5 respectively.

\subsection{Results}

$68 \%$ of the sample were users of contraception at the time of interview and of these $86 \%$ used modern reversible methods, (mainly the pill followed by injections). This points to the notion that knowledge of modern techniques has diffused into rural villages. The main ways of acquiring knowledge are mainly interpersonal methods with 75\% citing 'family health worker' and 32\% citing 'friends and relatives'.

For encouragement, only 1488 contacts were received relating to encouragement out of a potential 3620 contacts. Of these, the main sources of encouragement to the respondents were classed as relatives (987) and friends (320). The remaining 181 contacts were classed as opinion leaders, local Imams, teachers or village elders. For these groups the average encouragement score out of five was highest for relatives (2.54) and then friends (1.49). Relatively little encouragement was received from opinion leaders (mean score $=0.03$ ). 
The encouragement scores from all sources are clearly associated with the practice of contraception; this is illustrated in Figure 1. Those practising contraception have received significantly more encouragement than those who do not practice contraception, (the $\mathrm{P}$ values of all the differences was $<0.001$ ). The dominant source of interpersonal encouragement comes from relatives.

Figure 1: Encouragement and contraceptive practice

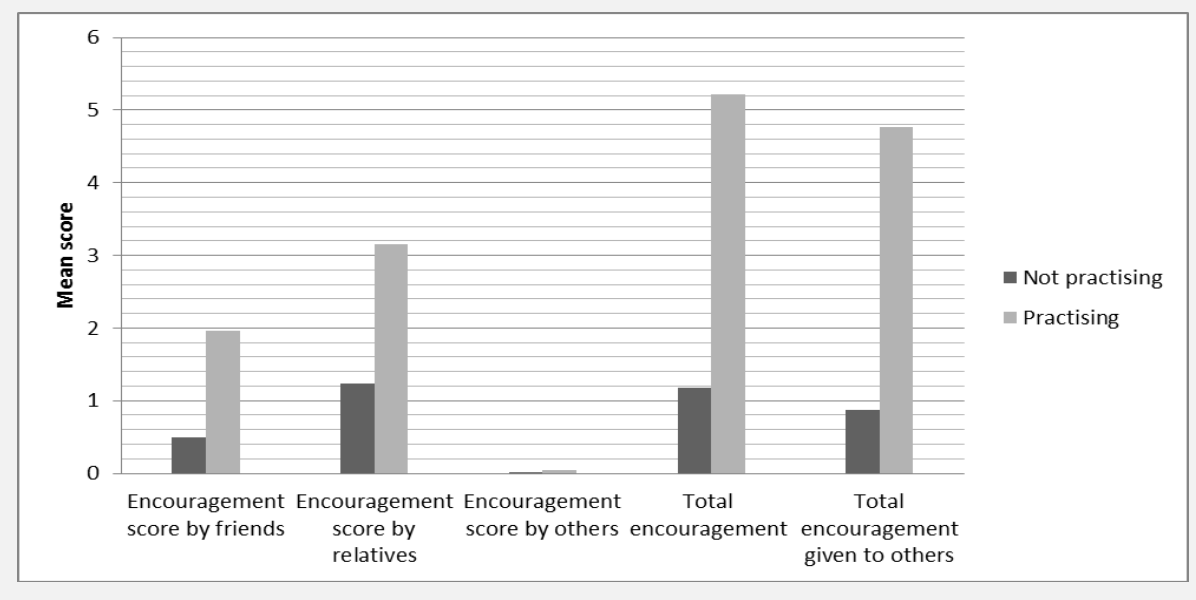

Those who practise contraception are also significantly more likely to encourage others to practise contraception when compared to those who do not practise contraception, $(\mathrm{P}<0.001)$.

A multivariate binary logistic regression model was used to determine the association of the strength of encouragement from relatives, friends and opinion leaders cited in an individual's network with current contraceptive use while controlling for their demographic and socio-economic status and husband's, family planning workers and mass media influence. The model is displayed in Table 2. To allow for the heterogeneity between villages caused by local environmental and political factors the villages were represented by dummy variables, (village 1 was taken as the baseline).

Table 2: Binary Logistic Model of the association of encouragement to current contraceptive use

Variable
Demographic and socio economic

Women's Age

Number of Children

Number of dead children

Women's level of education

Husbands level of education

Possession score

Female Autonomy score

Micro Credit Affiliation ( $\mathrm{y}=1)$

Religion ( 1 =Muslim, 0 = Other)

\section{Perceived Direct Influence}

Husbands influence

Mass media influence

Female welfare Assistants' influence

\section{Network Encouragement}

Friends encouragement

Relatives encouragement

Opinion leaders encouragement

Village effect (village $7=$ baseline)

Village_1

Village_2

Village_3

Village_4

Village_5
Coefficient Standard Error

.024

.173

$-.033$

.018

$-.102$

.071

.027

$-.004$

$-.152$

.140

.240

.411

.482

.218

$-.164$

$-1.119$

$-1.245$

.270

.553
.024

.107

.175

.194

.165

.083

.140

.268

.336

.030

.046

.034

.057

.062

.392

.562

.556

.573

.494

.512
.000

.000

.000

.316

.108

.852

.926

.537

.394

.849

.988

.651

.000

.002

$<.001$

1.126

1.150

1.258

1.619

1.271 


\begin{tabular}{lrrrr}
\hline Village_6 & .605 & .580 & .297 & 1.831 \\
Constant & -3.236 & .723 & .578 & 1.244
\end{tabular}

This model fitted well, correctly predicting $91 \%$ and $79 \%$ of the users and non-contraceptive users respectively (overall of $88 \%$ contraceptive users were correctly predicted). The pseudo $\mathrm{R}^{2}$ values of Cox and Snell and Negelkerke were $45.8 \%$ and $64.0 \%$ respectively. Compared to the first village, only villages 4 showed any significant association at the $5 \%$ level with contraceptive use. In this village, the respondents tended to be older, had less experience of child death, owned few possessions, tended to have higher Muslim representation, and were more remote than the other villages.

After controlling for the village effect, none of the demographic and socio-economic variables were found to be significant. Perceived husband's influence was associated with the likelihood of using contraception, suggesting that an ideological change had occurred amongst males. Influence by family welfare workers was also, as one would expect, associated with contraceptive use. Perceived mass media influence was also significantly positively associated with the likelihood of using contraception, confirming the importance and success of the mass media in Bangladesh.

The highest significant odds ratio (1.619) which had a significant positive association with current contraceptive use was encouragement by relatives; encouragement by friends was also positively associated with contraceptive use with a relatively high odds ratio of 1.509 .

Matrices of the nature of the encouragement between members of each village were then prepared. If no encouragement was given or the person was not quoted in the ego's network a zero was scored. If alter encouraged an ego then their "encouragement score" was entered and similarly for egos encouraging alters. This produced asymmetric association matrices for each village and these were entered into the SNA package UCINET, Borgatti, Everett and Freeman (2002) to allow sociograms depicting the ties between individuals weighted by the encouragement score to be formed and sociometric measures to be obtained. The sociogram formed from village 5 , which had the highest level of contraceptive use among our sample of villages (85\% were users) is presented in Figure 2.

Figure 2: Sociogram of encouragement ties for village 5

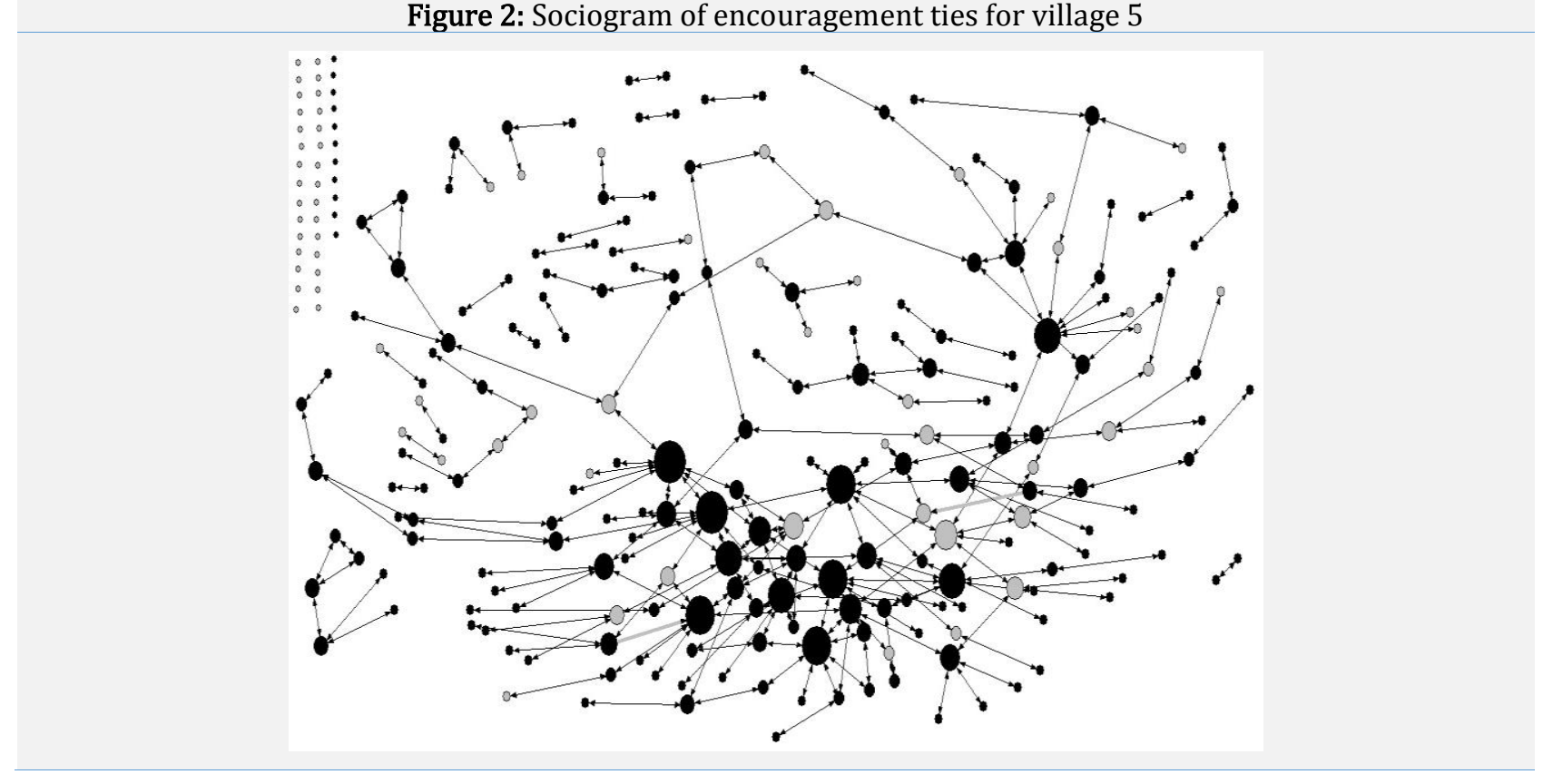

In Figure 2, black circles depict contraceptive users, grey circles are non-contraceptive users, empty circles are unknown practice and circle size is used to depict "centrality", the number of incoming ties and outgoing ties weighted in this case by encouragement strength. Reciprocal ties are indicated by black lines with an arrowhead at each end and non-reciprocal ties are shown by a thicker grey line with an arrow head at only one end. The matrixes of small circles in the top left corner of Figure 2 are isolates who did not record any encouragement. From this figure, it seems that being in a network where one encourages fertility use and receives encouragement make contraceptive use more likely. There is a cluster of actors in the bottom sector of Figure 2, which are mutually encouraging the use of contraception. The vast majority of the ties are reciprocal and there 
are hardly any non-reciprocal ties. Of the 41 isolates that got no declared encouragement to use contraception, only 11 of them practice contraception.

In village 3 , the practice of contraceptive use is much less than in village $5(36 \%$ compared with $85 \%)$ and the sociogram is displayed in Figure 3. This is a more fragmented network in which many of the central actors do not practise contraception. In this network, there are only a few reciprocal ties and non-reciprocal ties dominate. Of the 50 isolated actors (those who declared no encouragement to use contraception), only 13 practised contraception.

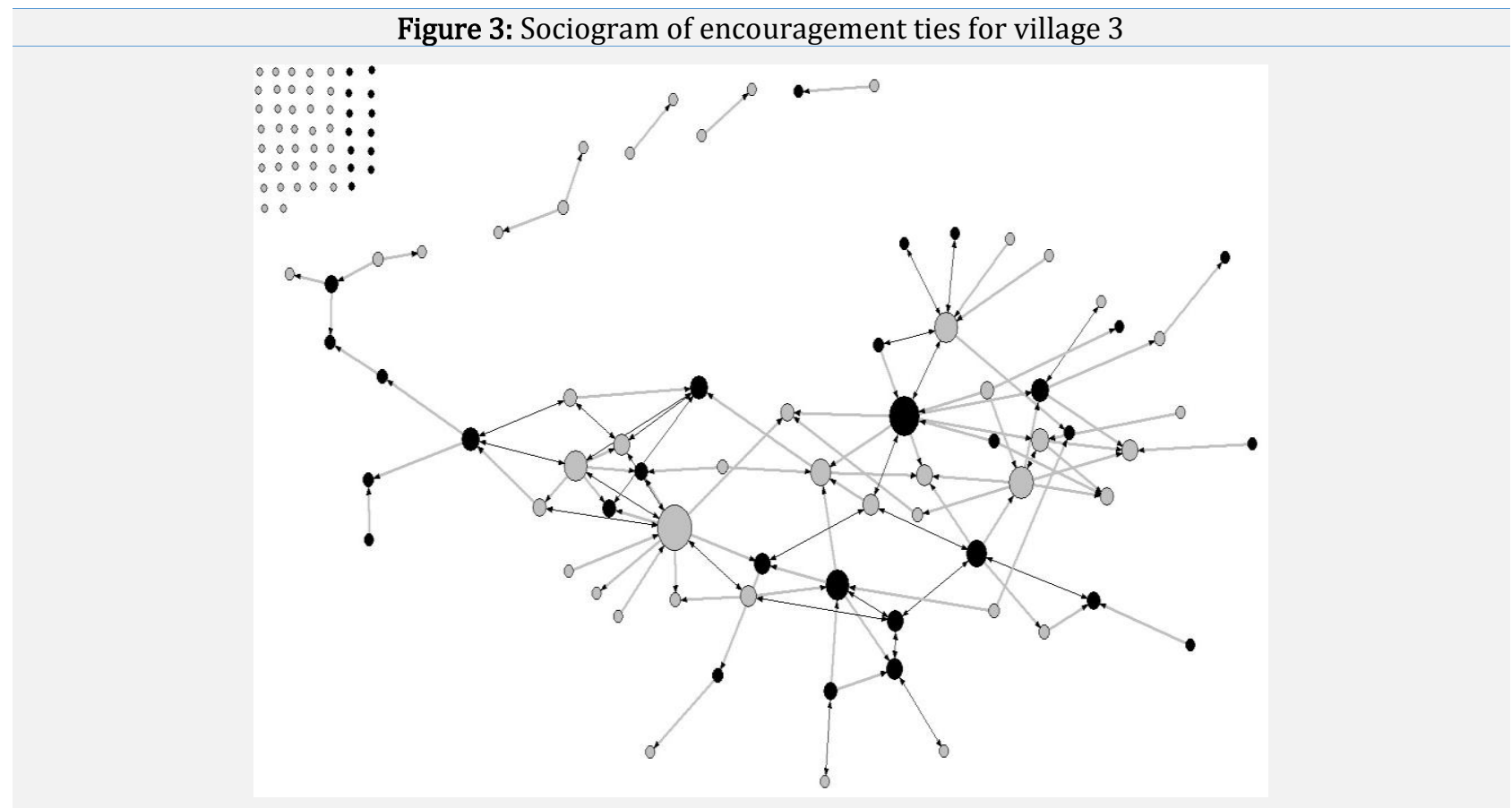

From the networks in-degree and out-degree centrality were computed - here in-degree centrality represents the amount of encouragement from others and out-degree represents the amount of encouragement given to others. These were computed at the village level and normalised on a 0 to 1 scale to allow comparison between villages with different numbers of network members. There is a high positive Pearson's Product Moment correlation between in-and-out degree centrality $(r=0.917, \mathrm{P}<0.001)$ giving strong evidence for the existence of reciprocal relationships. These normalised scores of in-and-out-degree were compared between those who practised and those who did not practise contraception. The mean scores for those who practised contraception are more than double that of those who did not practise. The respective centrality means for encouraging others and being encouraged by others were 0.475 and 0.472 for those practising contraception compared to 0.221 and 0.222 for those did not practise, the differences are statistically significant $(\mathrm{P}<0.001)$.

\subsection{Conclusion}

In this paper, we have investigated why women in rural Bangladesh have adopted and maintained the ideology of a small family norm, despite little progress in their economic fortunes. We found that many are in networks of friends and relatives that encourage the use of contraception, and if the respondent practises, contraception then they tend to encourage others to do so. Using a regression model to control for other influences, we found that the encouragement variables along with husbands influence, that of family welfare assistants and the mass media appear to have a larger association with the likelihood of using contraception than individual demographic and economic factors.

For most villages there was homogeneity in the associations derived; only villages 2 and 3 show any significant variation. Both these villages had high encouragement scores, in village 2 more husbands influence was high and the female autonomy score was low scores while village 3 had the highest mean number of children per mother and was universally Islamic.

Exploring the nature of reciprocity - the mutual encouragement in the social networks it was found that as one would expect that there were many more reciprocal ties in villages where contraceptive practice was high than those with low contraceptive rates. In these latter villages, ties between actors tended to be in only one direction. 
In the social networks of each village, encouragement given by others was measured by in-degree centrality and the encouragement given to others was measured by out-degree centrality. In and out-degree centrality were found to be strongly positively correlated and these scores were found to be statistically significantly higher among those who practised contraception were compared to those who do not practise contraception.

The results suggest that for rural Bangladesh, women's social networks have had a significant positive association with using contraception and encouragement within these networks is important. Our findings are contrary to those of Stewart-Williams, (2007). We found that relative's encouragement seems to make contraceptive use more likely than encouragement from friends. Encouragement at a personal level from opinion leaders seems to be more effective, but opinion leaders are not highly represented in personal networks of rural Bangladeshi women. This casts doubt on the argument given in a growing literature that the involvement of religious leaders in women's family-planning decision making can lead to more positive attitudes to contraception, as suggested by Underwood, Kamhawi and Nofal, (2013), Orubuloye et al., (2011) and AbuMoghli et al., (2010). The influence of the mass media and family welfare assistants is important; as these are conduits where by new ideas can be diffused in to networks. However, it is likely that these messages have to be endorsed by husbands and relatives who act as gatekeepers. Thus, we agree with Mullany, Hindin and Becker, (2005) that husbands especially need to be kept involved in family planning decision making. Important in our findings were that if relatives and friends encouraged the ego to use contraception and the ego reciprocated this encouragement then the use of contraception becomes very likely. This suggests that once the ideology of using contraception is accepted then sustained use is facilitated by the existence of reciprocal ties in tight and enduring social networks.

However, such cross sectional studies have limitations inhibiting making generalisations. Notably causality cannot be assumed and the nature of friendship varies between cultures as pointed out by Hruschka, (2010). White and Watkins, (2000) adds to this by exposing many measurement issues in measuring reciprocity in developing countries. These problems were attributed to the respondent either forgetting or being unwilling to declare some ties and the nature of other ties. This casts doubt on the reliability of studies in this area and we did find some indications of these problems as often reports on encouragement to or from the fourth and fifth friends were missing, especially so for village 7. Nevertheless, we do believe that we have found evidence on the nature of reciprocal links and their association with contraceptive use.

We forward the suggestion that social networks which evolve to give mutual encouragement to practice contraception help to sustain the ideational shift to low fertility in Bangladesh. This is manifested by prolonged contraceptive use despite economic turbulence villages may encounter. The network can be made more effective if opinion leaders can take part at a local and personal level and give endorsement at a face-to-face level in women's social networks. Key also to sustaining a low fertility regime will be the continuation of the role female welfare assistants at the village level and their participation in women's social networks. This is not to forget the role of Government and the mass media to remind individuals, especially husbands, of the economic, social and medical burdens of having many children.

This discussion leads to the following policy advice to sustain a regime of low fertility. Firstly governments and policy makers need to recognise the importance of networks of relatives; spouses and friends have in endorsing behaviour and if endorsed through reciprocal encouragement then behaviour change is likely to be sustainable. Secondly having made this recognition governments and policy makers need to take care in policy formation not to disturb these community based networks. Thirdly to maximise the impact of family network acceptance of contraception it is advisable to have face to face intervention of family welfare assistants to reinforce the message that limiting family size can lead to economic advantage and improvements in wellbeing. This last point can be made more effective if supported by general media communication and endorsement from opinion leaders on the benefits of limiting family size.

\section{References}

Abu-Moghli, F., Nabolshi, M., Khalaf, I., Suliman, W., (2010). Islamic religious leaders' knowledge and attitudes towards AIDS and their perception of people living with HIV/AIDS: a qualitative study, Scand. J. Caring Sci., 24: 655-662. http://dx.doi.org/10.1111/j.1471-6712.2009.00757.x

Amin, R., Li, Y., Ahmed, AU., (1996). Women's credit programs and family planning in rural Bangladesh, Intern. Family Pan. Persp., 22(4):158-162.

Baboloa, S., Vonrasek, C., (2005). Communication, ideation and contraceptive use in Burkina Faso: an application of the propensity score matching method, J Fam Plann Reprod Health Care, 31:207-212. http://dx.doi.org/10.1783/1471189054484022 
Bangladesh Centre for Communication Programs. 2003. Evaluation of Smiling Sun campaign. Dhaka: BCC, Dhaka, Bangladesh Centre for Communication Programs.

Borgatti, SP., Everett, MG., Freeman, LC., (2002). UCINET for Windows: Software for Social Network Analysis. Harvard: Analytic Technologies.

Borgati, SP., Everett, MG., Johnson, J C., (2013). Analyzing Social Networks, Sage, London.

Boulay, M., Valente, TW., (1999). The relationship of social affiliation and interpersonal discussion to family planning knowledge, Attitudes and Practice, Internat. Family Plan. Persp., 25(3): 112-118 \& 138.

Chandola, T., Marmot, M. and Siegrist J. (2007). Failed reciprocity in close social relationships and health: Findings from the Whitehall II study, J. of Psychosomatic Res, 63: 403-411. http://dx.doi.org/10.1016/j.jpsychores.2007.07.012

Caldwell, JC., Caldwell, BK., (2006). The causes of the Asian fertility decline, Asian Population Studies, 1 (1): 31 46. http://dx.doi.org/10.1080/17441730500125714

Cleland, J., Wilson, C. (1987). Demand theories of the fertility transition: an iconoclastic view. Pop. Stud., 41, 550. http://dx.doi.org/10.1080/0032472031000142516

Curry O., Roberts, SG., Dunbar RI., (2012). Altruism in social networks: Evidence for a "kinship premium". British Journal of Psychology, 104: 283-295. http://dx.doi.org/10.1111/j.2044-8295.2012.02119.x

Davis, K., (1945). The world demographic transition. Ann. Amer, Acad. Polit. and Soci, Sci. 273: 1-11.

Gayen, K. (2009). Modelling Influences of Communication: A study of the Fertility Behaviour of Women in Rural Bangladesh. LAP Lambert Academic Publishing, Bonn.

Gayen, K., Raeside R., (2007). Social networks, normative influence and health delivery in rural Bangladesh. Soc. Sci. \& Med., 65(6): 900-914. http://dx.doi.org/10.1016/j.socscimed.2007.03.037

Gayen, K., Raeside, R., (2010). Social networks and contraception practice of women in rural Bangladesh, Soc. Sci. \& Med. 71: 1584-1592. http://dx.doi.org/10.1016/j.socscimed.2010.08.002

Godley, J. 2001. Kinship networks and contraceptive choice in Nang Rong, Thailand, Intern. Family Plan. Persp., 27(1):4-10. http://dx.doi.org/10.2307/2673799

Hanneman, RA., Riddle, (2005). Introduction to Social Network Methods. Riverside, CA: University of California, Riverside (published in digital form at http://faculty.ucr.edu/ hanneman/ )

Hogan, B., Carrasco, JA. and Wellman B. (2007). Visualising personal networks: working with participant-aided sociograms. Field Methods, 19(2): 116-144. http://dx.doi.org/10.1177/1525822X06298589

Hruschka, DJ., (2010). Friendship: Development, ecology, and evolution of a relationship. Berkeley and Los Angeles, CA: University of California Press. http://dx.doi.org/10.1525/california/9780520265462.001.0001

Latkin CA., Forman V., Knowlton A., Sherman S. (2003). Norms, social networks and HIV-related risk behaviour's among urban disadvantaged drug users. Soc. Sci. \& Med., 56: 465-476. http://dx.doi.org/10.1016/S02779536(02)00047-3

Li, T., Zhang, Y., (2015). Social network types and the health of older adults: Exploring reciprocal associations, Soc. Sci. \& Med., 130: 59-68. http:// doi:10.1016/j.socscimed.2015.02.007

Luke DA., Harris K., (2007). Network analysis in public health, history, methods, and applications, Ann. Rev of Publ. Health, 28: 69-93. http://dx.doi.org/10.1146/annurev.publhealth.28.021406.144132

Madhavan, S., Adams, A., Simon, D. (2003). Women's networks and the social world of fertility behavior, Internat. Family Plan. Persp, 29(2):58-68. http://dx.doi.org/10.2307/3181059

Montgomery M., Casterline J. (1996). Social learning, social influence, and new models of fertility. Pop. \& Dev. Rev.,22 (Suppl.): 151-175. http://dx.doi.org/10.2307/2808010

Mullany, BC., Hindin, MJ., Becker, S., (2005). Can women's autonomy impede male involvement in pregnancy health in Katmandu, Nepal? Soc. Sci. \& http://dx.doi.org/10.1016/j.socscimed.2005.04.006

Orubuloye, IO., Brown, J., Sherard, D., Tushabe, B., Abdur-Rahman, A., (2011). Ritual communication and changing gender norms in Uganda: A study of African transformation, J. Commun, 61:197-218. http://dx.doi.org/10.1111/j.1460-2466.2011.01537.x

Ryan, L., (2011). 'Migrants' social networks and weak ties: accessing resources and constructing relationships post-migration', Sociological Review 59 (4): 707-724. http://dx.doi.org/10.1111/j.1467954X.2011.02030.x

Stewart-Williams. S., (2007). Altruism among kin vs. non-kin: Effects of cost of help and reciprocal exchange. Evolution and Human Behavior, 28: 193-198. http://dx.doi.org/10.1016/j.evolhumbehav.2007.01.002

Stoebenau, K., Valente, TW., (2003). Using network analysis to understand community-based programs: A case study from Highland Madagascar, Internat. Family Plan. Persp., 29(4) 167-173 http://dx.doi.org/10.2307/3181045

UN, (2016). Population Division, United Nations Department of Economic and Social Affairs, http://www.un.org/en/development/desa/population/theme/trends/index.shtml 
Underwood, C., Kamhawi, S., Nofal, A., (2013). Religious leaders gain ground in the Jordanian family-planning movement, Inter. J. Gynaecology \& Obstetrics, 123(1):e33-e37. http://dx.doi.org/10.1016/j.ijgo.2013.07.006

Valente TE., (2010). Social Networks and Health, Models, Methods and Applications. Oxford University Press, Oxford. http://dx.doi.org/10.1093/acprof:oso/9780195301014.001.0001

Van der Hulst, RC., (2009). Introduction to social network analysis (SNA) as an investigative tool, Trends Orgasn Crim, 12: 101-121. http://dx.doi.org/10.1007/s12117-008-9057-6

Valente, TW, Watkins, SC, Jato, MN., (1997). Social network associations with contraceptive use among Cameroonian women in voluntary associations. Soc, Sci. \& Med., 45: 677-687. http://dx.doi.org/10.1016/S0277-9536(96)00385-1

Wassermann S, Faust K. Social network analysis. Cambridge: Cambridge University Press, 1984.

Wey, T., Blumstein, DT, Shen W., Jordán, F., (2008). Social network analysis of animal behaviour: a promising tool for the study of sociality, Animal Behaviour, 2008, 75: 333-344. http://dx.doi.org/10.1016/j.anbehav.2007.06.020

World Bank. (2014). World Bank Indicators - Mortality, http://data.worldbank.org/indicator/SP.DYN.IMRT.IN, [Date Accessed 10th June 2014].

White K., Watkins C., (2000). Accuracy, stability and reciprocity in informal conversational networks in rural Kenya, Soc. Networks, 2000, 22: 337-355. http://dx.doi.org/10.1016/S0378-8733(00)00030-7

Xue, M., (2013). Altruism and reciprocity among friends and kin in a Tibetan village, evolution and human behavior, 34: 323-329. http://dx.doi.org/10.1016/j.evolhumbehav.2013.05.002 